\title{
Application of behavioural psychology principles to self-care programmes for people living with leprosy
}

\author{
Sopna Mannan Choudhury ${ }^{\mathrm{a}}$, Laura Kudrna ${ }^{\mathrm{a}}$, Bahadir Celiktemur ${ }^{\mathrm{b}} \&$ \\ Richard James Lilford ${ }^{\mathrm{a}}$ \\ ${ }^{a}$ Institute of Applied Health Research, College of Medical and Dental \\ Sciences, University of Birmingham, Edgbaston, Birmingham B15 2TT, UK \\ ${ }^{\mathrm{b}}$ The Leprosy Mission England and Wales, Goldhay Way, Orton Goldhay, \\ Peterborough PE2 5GZ, UK
}

Submitted 30 November 2021; Accepted 1 December 2021

Keywords: COM-B model, self-care, interventions, behaviour, behavioural psychology

\section{Introduction}

To prevent and manage ulcers, people must make changes to successfully engage in self-care practices and adhere to self-care guidelines. Self-care interventions aim to achieve long term behaviour change by instilling a coordinated set of activities-personal care tasks-in the individual's daily life. ${ }^{1-8}$ Motivation to engage in such activities can be augmented if the work of facilitators and peer trainers is informed by modern psychological and behavioural theories.

In these guidelines, we employ the Capability, Opportunity, Motivation Behavioural framework (COM-B $)^{9}$ to guide those who will design interventions to promote and sustain self-care interventions. ${ }^{4}$ We provide a brief summary of the COM-B model, followed by guidance for those who design and deliver self-care interventions on utilising practical behaviour change methods for successful self-care programmes.

\section{The COM-B model}

The COM-B system suggests that behaviour change is dependent on the influence and interaction of three factors - capability, opportunity and motivation. The model identifies nine broad categories of things one can do to change the capability, opportunity and/or motivation of a person to engage in a behaviour, and these are referred to as intervention functions. These intervention functions are given in Figure 1.9

Correspondence to: Sopna Mannan Choudhury, Institute of Applied Health Research, College of Medical and Dental Sciences, University of Birmingham, Edgbaston, Birmingham B15 2TT, UK

(e-mail: s.m.choudhury.1@bham.ac.uk) 
Sources of behaviour

Intervention functions

Policy categories

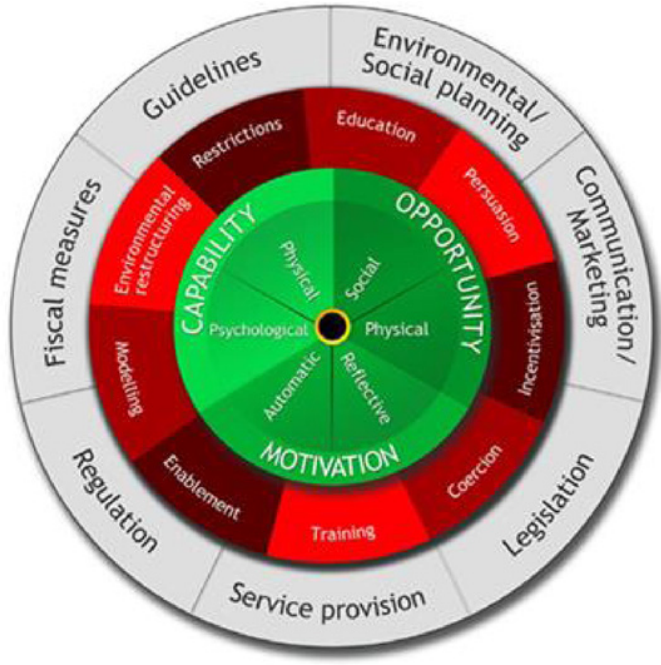

Figure 1. The behaviour change wheel. (Reproduced with permission from Michie et al. ${ }^{9}$.)

A workshop was held in Nepal involving policy makers and people affected by leprosy, which used COM-B to identiy barriers and facilitators of self care for leprosy. The results are shown in Figure 2, (adapted from Lilford et al. ${ }^{10}$ ).

Motivation. Conscious motivation builds on decision-making and resilience. Subconscious clues from the social environment are often negative, but peer groups might engender resilience.

Capability to use preventive care includes skills in, and knowledge of, how to look after extremities and avoid repeated injury.


component. The physical component encompasses distance from places of care and access to a self-care peersupport group and access to protective footwear. The social component includes social stigma that may prevent people from using protective footwear or presenting early. The need to earn a living, sometimes through physical work, limits capability for many with leprosy in order to rest the affected limb.

Figure 2. Barriers and facilitators identified during the consultation, mapped onto the COM-B framework. 
In the context of leprosy self-care, capability includes understanding the benefits of self-care and having the requisite practical skills for self-care (described in the paper by Darlong ${ }^{11}$ in this series). Opportunity includes having the time and money to support self-care. Depending on the context and circumstances of the individual, this can range from having access to clean water to having sufficient time to rest and heal where necessary. Opportunity also involves a supportive family and community environment. Finally, motivation can be understood as the desire to undertake self-care. Much human motivation arises subconsciously, and this is the basis of 'nudge' theory. ${ }^{12}$

\section{CAPABILITY}

Education provides information about the potentially beneficial effects of self-care practices (and conversely, the implications of not carrying them out), while training provides people with the skills required to successfully complete those practices and avoid unnecessary risk. Both educational and training interventions have been carried out extensively with leprosyaffected people, by both health care professionals and peers. It is important to recognise that barriers to self-care may arise from limitations to physical capabilities too. For example, it may be difficult to attend to leprosy ulcers due to physical disabilities like vision impairment, limiting the ability to engage in self-care behaviour.

\section{OPPORTUNITY}

Leprosy is a disease of poverty and, as such, people affected by leprosy may not have access to the necessary time, tools or conditions (e.g. easy access to running water) to undertake self-care practices. Further, it is not always possible to reduce competing time demands, e.g. the ability to rest and soak limbs rather than earn a living. Working with people to change the context in which behaviour will or will not occur might help promote self-care. Providing resources, ensuring the supply chain for materials, or ensuring that suitable materials are available locally, are all critical in ensuring a successful intervention. Initiatives that reduce stigma and create positive cultures and social norms around self-care draw upon social opportunities to change self-care behaviours.

\section{MOTIVATION}

Motivation can be an issue for some people affected by leprosy and may affect a person's functioning. Targeting reflective motivation could involve increasing knowledge about the condition and treatment options, understanding self-care processes, and discussing the benefits of practising self-care. Critical factors in motivating people to self-care are reflective motivation and stigma. The concept of self-efficacy, an individual's belief in their capacity to carry out behaviours and exert control over their own lives, is particularly relevant for people affected by leprosy. ${ }^{13}$ Improving self-efficacy should be a key component of many future interventions. Beliefs about the benefits of self-care must outweigh the consequences of not practising it, particularly concerning stigma. Interventions that reduce or avoid the potential for stigma must be adopted. 
Alongside reflective motivation, it is important to consider automatic motivation-that is, the idea that what people do is not so much thought about in a conscious and reflective sense; it simply comes about in an unconscious and automatic sense. Automatic motivation includes emotional reactions, desires, impulses, inhibitions, drive states, and reflex responses. ${ }^{14}$ For example, whether people choose to select a particular drink depends more on how it is displayed than on any reflective or conscious reasoning about selecting that drink. ${ }^{15}$ Similarly, self-care may occur automatically in response to environmental and contextual cues. For example, making a public commitment to engage in self-care in a particular situation may automatically trigger self-care behaviour in that situation. ${ }^{16,17}$ The person who provides information about self-care ('the messenger') may be more important for changing behaviour than the message content and wording. Feelings about leprosy, such as whether the condition is perceived in strong affective terms like 'disgust', may automatically influence self-care behaviour too. ${ }^{18,19}$

These behaviours are impacted by many factors that can be encompassed by COM-B. The need to earn a living, for example, by walking miles every day to the field or through physical work, often limits opportunity and presents an environmental barrier for many people living with leprosy. This is reflected in the findings of a study in Ethiopia $^{2}$ where people with a higher income were more likely to practice self-care. Further, opportunity entails having the requisite tools and materials to carry out self-care practices. For example, having access to creams and/or dressings for cracks on the skin. ${ }^{20}$ Group interactions are a social opportunity factor influencing motivation for many people, but the distance required to travel to the group may prevent or limit opportunities for peer interaction. Social support (e.g. from friends and family) is critical in terms of opportunities to change behaviour, while stigma (including sometimes self-stigma) is demotivating. It is not always possible to reduce competing time demands; for example, it is difficult for farmers to avoid putting weight on vulnerable surfaces of the body at harvest time. Working with people to change the context in which a behaviour will or will not occur, will likely be helpful in promoting self-care. Providing resources, ensuring the supply chain for materials, or making certain that suitable materials are available locally are all critical in ensuring a successful intervention. Motivation can be an issue for some people affected by leprosy and may affect a person's functioning. Targeting motivation could involve increasing knowledge about the condition and treatment options, understanding self-care processes, and discussing the benefits of practising self-care. Critical aspects of motivation are its reflective and unconscious or automatic components. Reflective motivation includes concerns about the likely negative consequences of ulcers and subsequent disability through not doing it (e.g. lack of marriage prospects or further disability). ${ }^{21}$ Ensuring that people have reflected on their motivations and have a plan to carry out self-care and risk reduction measures (for example, always soaking feet before bedtime; always wearing shoes outdoors) that will become a regular habit are also important. Automatic habits could be encouraged by empowering people to design their environment in ways that promote self-care, such as by making sure that appropriate footwear and self-care facilities are easily accessible around the home and at work. ${ }^{22}$ 
We crystallise the operation of the COM-B model for leprosy self-care in Figure 3. In addition, we list the specific actions of community self-care interventions identified in our scoping review of self-care interventions in this series (Ilozumba, et al.) ${ }^{23}$ organised by the COM-B intervention functions, in Table 1 . The purpose of this was to identify the prevalence of different intervention functions in the context of self care of leprosy in low- and middleincome countries (LMICs), which may inform future interventions and initiatives. After data extraction, two of the authors (SC and LK) independently coded the intervention functions. They used the definition of intervention functions from Michie, et al. ${ }^{24}$ (see Table 2). After coding, their agreement was 56\% (29/52 identified interventions). After further discussion, their agreement reached $100 \%$ (49/49 identified interventions). The most common intervention functions were 'training' $(13 / 49,27 \%)$, followed by 'education' $(12 / 49,24 \%)$ and 'enablement' (12/49, 24\%). Some intervention functions used 'environmental restructuring' $(5 / 49,10 \%)$ and 'modelling' $(4 / 49,8 \%)$, whereas the intervention functions 'persuasion' $(1 / 49,2 \%)$, 'incentivisation' $(1 / 49,2 \%)$ and 'coercion' $(1 / 49,2 \%)$ were less common. The intervention function 'restriction' was not identified in any of the interventions. Future research could consider whether there are barriers and facilitators of self-care for people with leprosy in LMICs that could be addressed using these intervention functions, particularly with some of the lesser used intervention functions such as environmental restructuring or persuasion.



Figure 3. Causal pathway for self-care. 


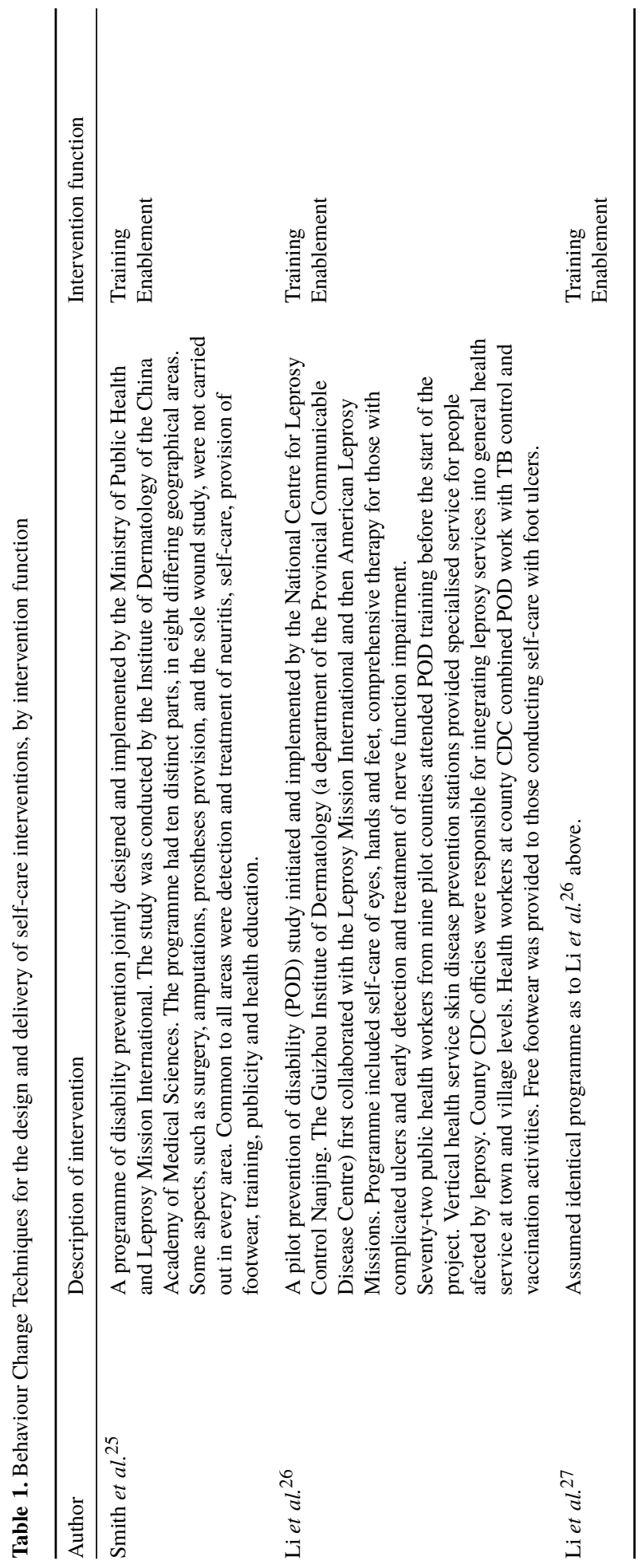









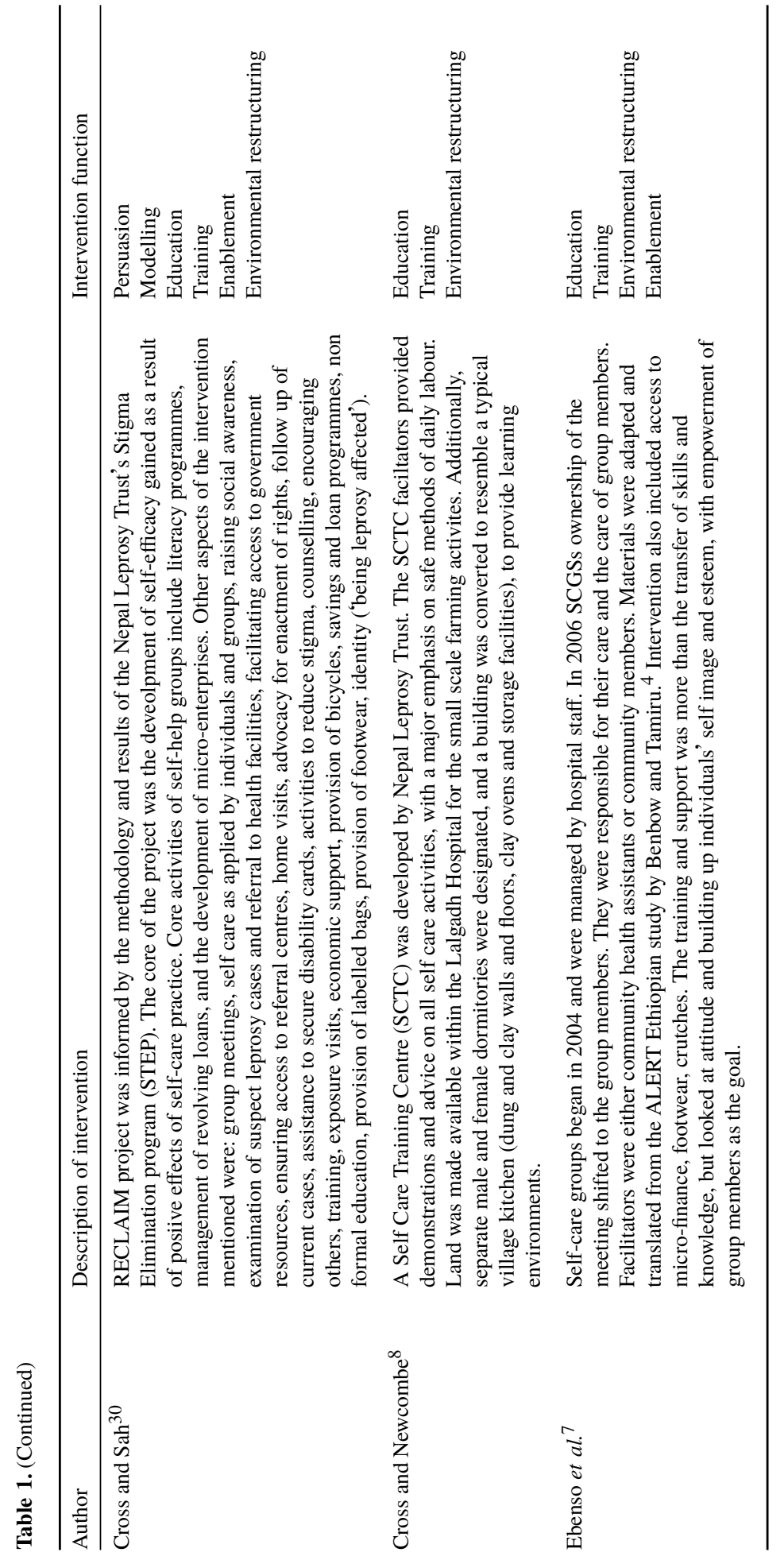




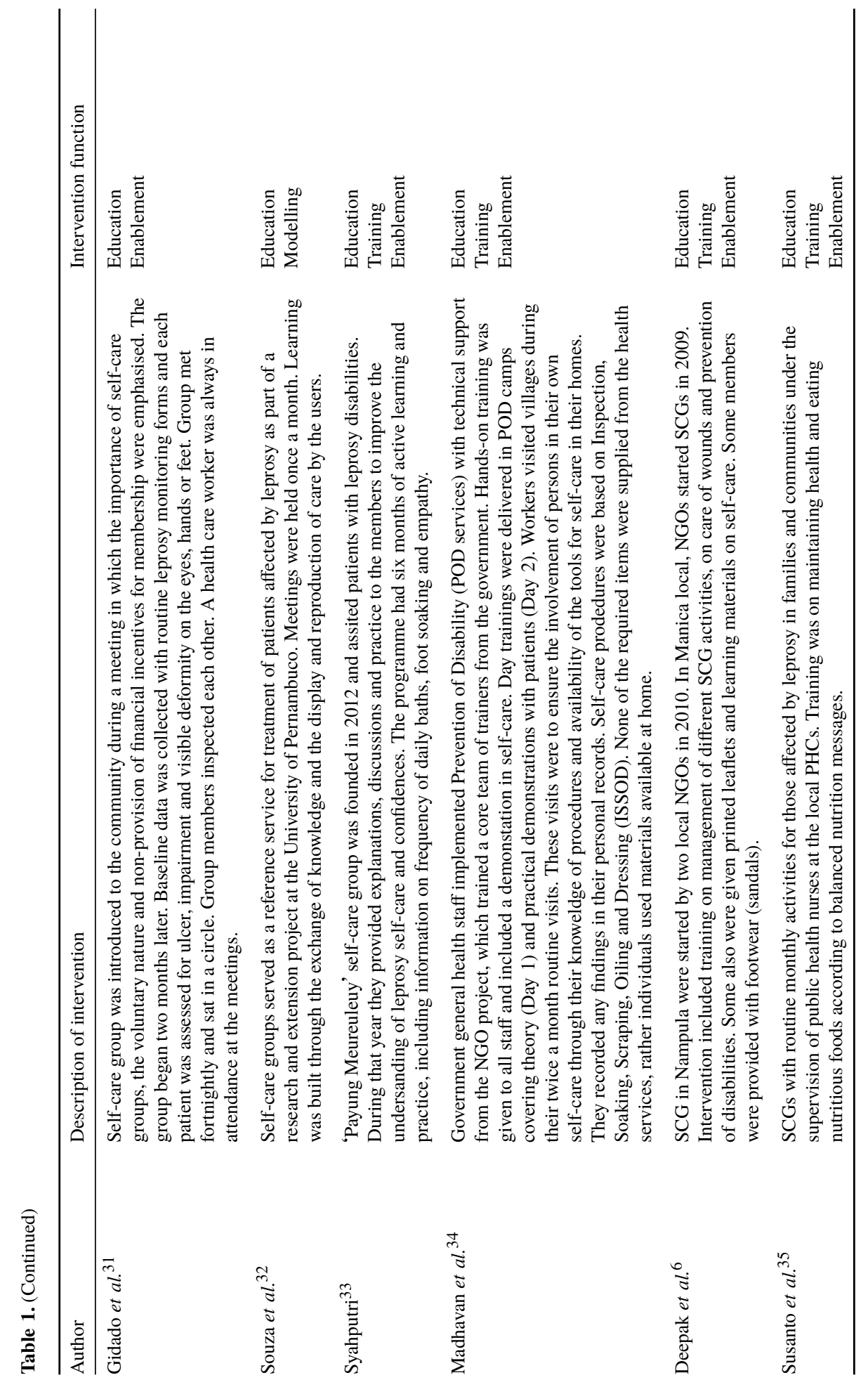


Table 2. Intervention function definition and examples (from Michie et $a l .{ }^{24}$ )

\begin{tabular}{|c|c|c|}
\hline $\begin{array}{l}\text { Intervention } \\
\text { function }\end{array}$ & Definition & Example \\
\hline Education & Increasing knowledge or understanding & $\begin{array}{l}\text { Providing information to promote healthy } \\
\text { eating }\end{array}$ \\
\hline Persuasion & $\begin{array}{l}\text { Using communication to induce positive or } \\
\text { negative feelings or stimulate action }\end{array}$ & $\begin{array}{l}\text { Using imagery to motivate increases in } \\
\text { physical activity }\end{array}$ \\
\hline Incentivisation & Creating an expectation of reward & $\begin{array}{l}\text { Using prize draws to induce attempts to stop } \\
\text { smoking }\end{array}$ \\
\hline Coercion & $\begin{array}{l}\text { Creating an expectation of punishment or } \\
\text { cost }\end{array}$ & $\begin{array}{l}\text { Raising the financial cost to reduce excessive } \\
\text { alcohol consumption }\end{array}$ \\
\hline Training & Imparting skills & $\begin{array}{l}\text { Advanced driver training to increase safe } \\
\text { driving }\end{array}$ \\
\hline Restriction & $\begin{array}{l}\text { Using rules to reduce the opportunity to } \\
\text { engage in the target behaviour (or to increase } \\
\text { the target behaviour by reducing the } \\
\text { opportunity to engage in competing } \\
\text { behaviours) }\end{array}$ & $\begin{array}{l}\text { Prohibiting sales of solvents to people under } \\
18 \text { to reduce use for intoxication }\end{array}$ \\
\hline $\begin{array}{l}\text { Environmental } \\
\text { restructuring }\end{array}$ & Changing the physical or social context & $\begin{array}{l}\text { Providing on-screen prompts for GPs to ask } \\
\text { about smoking behaviour }\end{array}$ \\
\hline Modelling & $\begin{array}{l}\text { Providing an example for people to aspire to } \\
\text { or imitate }\end{array}$ & $\begin{array}{l}\text { Using TV drama scenes involving safe-sex } \\
\text { practices to increase condom use }\end{array}$ \\
\hline Enablement & $\begin{array}{l}\text { Increasing means/reducing barriers to } \\
\text { increase capability (beyond education and } \\
\text { training) or opportunity (beyond } \\
\text { environmental restructuring) }\end{array}$ & $\begin{array}{l}\text { Behavioural support for smoking cessation, } \\
\text { medication for cognitive deficits, surgery to } \\
\text { reduce obesity, prostheses to promote } \\
\text { physical activity }\end{array}$ \\
\hline
\end{tabular}

\section{Conclusion}

Modern psychological and behavioural theory should inform self-care programmes. It should be written into intervention descriptions and facilitator training manuals, and it should inform interaction with people affected by leprosy. Subtle changes from the environment can impact on human motivation through automatic and unconscious pathways, and has been used to promote positive behavioural change in many aspects of life, from encouraging exercise to reducing littering. It can also be applied to self-care behaviours.

\section{Ethics approval}

Not required.

\section{Competing interests}

The authors have no competing interests. 


\section{Funding}

This research was funded by the National Institute for Health Research (NIHR: 200132) using UK Aid from the UK Government to support global health research. BC is also funded by The Leprosy Mission England and Wales. RJL and LK are also funded by NIHR Applied Research Collboration (ARC) West Midlands. The views expressed in this publication are those of the author(s) and not necessarily those of the NIHR or the UK Department of Health and Social Care.

\section{Authors' contributions}

SC, BC, LK, RJL: contributed to the development and editing of the manuscript. RJL: Director of the NIHR RIGHT funded project at University of Birmingham, contributed to the conception of this review, and critically evaluated the intellectual content. LK: contributed and provided expert knowledge on the COM-B model and its behaviour change techniques. SC and LK extracted data and coded the intervention functions of the self-care interventions identified in scoping review by Ilozumba et $a .^{23}$

\section{Acknowledgements}

We acknowledge the contribution of other members of the NIHR RIGHT grant team including Jo Sartori (University of Birmingham), and Dr. Holly Gwyther and Dr. Joydeepa Darlong for their initial work on the development of the guidelines, and the Scientific Guidelines and Advisory Committee and its chair, Dr. Paul Saunderson. We would also like to acknowledge Sian Arulanantham from The Leprosy Mission England and Wales for her continued support with all our work, and for supporting BC. We also acknowledge Dr. Onaedo Ilozumba for identifying the articles in the scoping review in this Series, used here for the identification of behaviour change techniques for the design and delivery of self-care interventions, by intervention function.

\section{References}

1 Abera M, Lemma G. The role of support groups in raising the self-concept of people affected by leprosy: an evaluation study in Ethiopia. Asia Pac Disabil Rehabil J, 2003; 14: 55-62.

2 Abera M, Lemma G. The effectiveness of self-care support groups in the prevention and management of ulcers: an evaluation in Ethiopia. Asia Pac Disabil Rehabil J, 2003; 14(1): 43-50.

3 Beise K, van Brakel W, Kadri Sewa A, Sumasto E, Arief M, Golo P et al. Overcoming Disabling Barriers: Perceptions of People Affected by Leprosy in Four Indonesian Self-Help Group. Leeds: University of Leeds, 2012.

4 Benbow C, Tamiru T. The experience of self-care groups with people affected by leprosy: ALERT, Ethiopia. Lepr Rev, 2001; 72(3): 311-321.

5 Cross H, Choudhary R. Self care: a catalyst for community development. Asia Pac Disabil Rehabil J, 2005; 16(2): 100-114.

6 Deepak S, Hansine PE, Braccini C. Self-care groups of leprosy-affected people in Mozambique. Lepr Rev, 2013; 84(4): 283-291.

7 Ebenso J, Muyiwa LT, Ebenso BE. Self care groups and Ulcer prevention in Okegbala Nigeria. Lepr Rev, 2009; 80(2): 187-196.

8 Cross H, Newcombe L. An intensive self-care training programme reduces admissions for the treatment of plantar ulcers. Lepr Rev, 2001; 72(3): 276-284.

9 Michie S, Atkinson L, West R. The Behaviour Change Wheel A Guide to Designing Interventions. Great Britain: Silverback Publishing, 2014.

10 Lilford RJ, Napit I, Sartori J. In: Lilford RJ (ed.), NIHR CLAHRC West Midlands News Blog. University of Warwick: NIHR CLAHRC WM, 2019. Available from: https://clahrcwmblog.wordpress.com/2019/01/18/barri ers-and-facilitators-to-self-care-of-leprosy/\#GB20190118_Ref1. 
11 Darlong J. Self-care in leprosy at the front line. Lepr Rev, 2021; 92(4): 356-365.

12 Maslow AH. A theory of human motivation. Psychol Rev, 1943; 50(4): 370-396.

13 Dennis CL. Peer support within a health care context: a concept analysis. Int J Nurs Stud, 2003; 40(3): 321-332.

14 Whittal A, Atkins L, Herber O. What the guide does not tell you: reflections on and lessons learned from applying the COM-B behavior model for designing real life interventions. Transl Behav Med, 2021; 11(5): 1122-1126.

15 North AC, Hargreaves DJ, McKendrick J. In: Store Music Affects Product Choice. UK: Nature Publishing Group, 1997; p. 132.

16 Dolan P, Hallsworth M, Halpern D, King D, Metcalfe R, Vlaev I. Influencing behaviour: the mindspace way. J Econ Psychol, 2012; 33(1): 264-277.

17 Meeker D, Knight T, Friedberg M, Linder J, Goldstein N, Fox C et al. Nudging guideline-concordant antibiotic prescribing: a randomized clinical trial. JAMA Int Med, 2014; 174(3): 425-431.

18 Jin Y, Ma H, Jiménez-Herrera M. Self-disgust and stigma both mediate the relationship between stoma acceptance and stoma care self-efficacy. $J$ Adv Nurs, 2020; 76(10): 2547-2558.

19 Scott BE, Lawson DW, Curtis V. Hard to handle: understanding mothers' handwashing behaviour in Ghana. Health Policy Plann, 2007; 22(4): 216-224.

20 Colella TJ, King KM. Peer support. An under-recognized resource in cardiac recovery. Eur J Cardiovasc Nurs, 2004; 3(3): 211-217.

21 Solomon P. Peer support/peer provided services underlying processes, benefits, and critical ingredients. Psychiatr Rehabil J, 2004; 27(4): 392-401.

22 Dolan P. Happiness by Design: Finding Pleasure and Purpose in Everyday Life. UK: Penguin, 2014.

23 Ilozumba O, Lilford RJ. Self-care programmes for people living with leprosy: a scoping review. Lepr Rev, 2021; 92(4): 317-337.

24 Michie S, van Stralen MM, West R. The behaviour change wheel: a new method for characterising and designing behaviour change interventions. Implement Sci, 2011; 6: 42.

25 Smith WCS, Zhang G, Zheng T, Watson JM, Lehman LF, Levert P. Prevention of impairment in leprosy; results from a collaborative project in China. Int J Lepr, 1995; 63(4): 507-517.

$26 \mathrm{Li} \mathrm{J}, \mathrm{Mu} \mathrm{H}, \mathrm{Ke} \mathrm{W}$, Bao X, Wang Y, Shen LM et al. Government health workers as implementers of prevention of disability measures: an assessment of a prevention of disability project in selected counties of Guizhou Province, People's Republic of China. Lepr Rev, 2008; 79(3): 295-302.

27 Li J, Mu H, Ke W, Bao X, Wang Y, Wang Z et al. The sustainability of self-care in two counties of Guizhou Province, Peoples' Republic of China. Lepr Rev, 2008; 79(1): 110-117.

28 Hounsome N, Kinfe M, Semrau M, Ali O, Tesfaye A, Mengiste A et al. Economic assessment of a communitybased care package for people with lower limb disorder caused by lymphatic filariasis, podoconiosis and leprosy in Ethiopia. Trans R Soc Trop Med Hyg, 2020; 114(12): 1021-1034.

29 Van't Noordende AT, Wubie Aycheh M, Tadesse T, Hagens T, Haverkort E, Schippers AP. A family-based intervention for prevention and self-management of disabilities due to leprosy, podoconiosis and lymphatic filariasis in Ethiopia: a proof of concept study. PLoS Negl Trop Dis, 2021; 15(2): e0009167.

30 Cross H, Kumar Sah A. The experiences and attitudes of people affected by leprosy who voluntarily undertake leprosy services in Nepal. Lepr Rev, 2014; 85(3): 224-231.

31 Gidado M, Obasanya JO, Adesigbe C, Huji J, Tahir D. Role of positive deviants among Leprosy self-care groups in Leprosy settlement, Zaria, Nigeria. J. Community Med Prim Health Care, 2011; 22: 1-2.

32 Souza NN, Belmonte MdL, Alves MGT, do Nascimento RD, Gomes MF, dos Santos DCM. Self-care in leprosy from the perspective of operative groups: a qualitative approach. Online Braz J Nurs, 2021; 20: 1-12.

33 Syahputri VN. Reduction of leprosy disabilities through self-care group "Payung Meureuleuy": a case study in Tripa Makmur Sub District, Nagan Raya Regency. Adv Sci Lett, 2017; 23(4): 3507-3510.

34 Madhavan K, Vijayakumaran P, Ramachandran L et al. Sustainable leprosy related disability care within integrated general health services: findings from Salem District, India. Lepr Rev, 2007; 78(4): 353-361.

35 Susanto T, Dewi E, Rahmawati I. The experiences of people affected by leprosy who participated in self-care groups in the community: a qualitative study in Indonesia. Lepr Rev, 2017; 88(4): 543-553. 